\title{
Pecuária leiteira em uma colônia de agricultores familiares no município de Palmeira, Paraná ${ }^{1}$
}

\author{
Joelcio Eurich ${ }^{*}$, Pedro Henrique Weirich Neto ${ }^{3}$, Carlos Hugo Rocha ${ }^{3}$
}

$10.1590 / 0034-737 X 201663040004$

\section{RESUMO}

A pecuária leiteira é segmento fundamental para o desenvolvimento econômico da agricultura de base familiar de várias regiões brasileiras. Este trabalho objetivou analisar a tipologia dos produtores e quantificar economicamente a produção leiteira da colônia de agricultores familiares "Quero-Quero", em Palmeira, PR. Do total, 90\% dos produtores são caracterizados como agricultores familiares e sua relação social-fundiária é de 6,33 ha por pessoa ocupada. O Valor Bruto da Produção leiteira - VBPl encontrado representa cerca de 15\% de todo o VBPl do município, ressaltando a importância fundamental da produção dessa comunidade para a economia local e para o município.

Palavras-chave: pecuária leiteira; desenvolvimento rural; agricultura camponesa.

\section{ABSTRACT}

\section{State of the art of dairy production in a family farming colony in Palmeira, Paraná, Brazil}

The dairy sector is fundamental to the economic development of family-based farming in many regions of Brazil. This study aimed to analyze the typology of producers and quantify the cost of milk production in the small colony of farmers "Quero-Quero" in Palmeira - PR. Of the total, 90\% of producers are characterized as family farmers and the social/land relationship is 6.33 ha per person employed. The gross value of milk production (GVPm) represents about $15 \%$ of all GVPm of the municipality, emphasizing the fundamental importance of the production of this community to the local economy and for the city.

Key words: dairy livestock; rural development; peasant agriculture.

\footnotetext{
Submetido em 02/07/2013 e aprovado em 12/07/2016.

Trabalho de especialização em agronegócio do primeiro autor.

${ }^{2}$ Universidade Estadual de Ponta Grossa, Laboratório de Mecanização Agrícola-Lama, Programa de Pós-Graduação em Agronomia, Ponta Grossa, Paraná, Brasil. joe.eurich@gmail.com. ${ }_{3}^{3}$ Universidade Estadual de Ponta Grossa, Laboratório de Mecanização Agrícola-Lama, Departamento de Ciência do Solo e Engenharia Agrícola, Ponta Grossa, Paraná, Brasil. lama1 @ uepg.br; chrocha@uepg.br

*Autor para correspondência: joe.eurich@gmail.com
} 


\section{INTRODUÇÃO}

A atividade leiteira é segmento relevante para o desenvolvimento econômico de diversas regiões brasileiras, pois permite a permanência do homem no campo, reduzindo as pressões sociais nas áreas urbanas, decorrentes da migração massiva do meio rural, e minimizando o desemprego e a exclusão social.

O leite é produzido, em todo o mundo, em grandes, médias e pequenas propriedades. Em sistemas intensivos, predominantemente em países desenvolvidos e, de forma extensiva, mais comumente nos países em desenvolvimento. Entretanto, tradicionalmente, a atividade leiteira em todo o mundo tem a característica de se desenvolver, em sua maioria, em propriedades administradas e exploradas por mão de obra familiar (Mezzadri, 2005).

O Sistema Agroindustrial do Leite está presente em todo território nacional e é um importante gerador de empregos, renda e tributos (Martins, 2004). Segundo o Instituto Brasileiro de Geografia e Estatística - IBGE (2006), a produção de leite no Brasil tem crescido continuamente desde 1970, ultrapassando os 20 bilhões de litros em 2006, 12,4\% superior à produção obtida em 1996. Observou-se redução do total de vacas ordenhadas, o que significa aumento de produtividade de $22,1 \%$, de $1.307 \mathrm{~L} \mathrm{vaca}^{-1}$ $\mathrm{ano}^{-1}$, em 1996, para 1.596 $\mathrm{L} \mathrm{vaca}^{-1}$ ano $^{-1}$ em 2006. Em 2006, 1.349 milhões de estabelecimentos declararam trabalhar com pecuária de leite. Minas Gerais é o maior produtor nacional, com $27,9 \%$ da produção total, superior à soma da produção das regiões nordeste e centro-oeste. A seguir, estão os estados do Rio Grande do Sul (a maior produtividade: $2.501 \mathrm{~L} \mathrm{vaca}^{-1}$ ano $^{-1}$ ), o Paraná e Santa Catarina. $\mathrm{O}$ conjunto de produtores paranaenses que atuam no mercado de leite representa cerca de $25 \%$ do total dos produtores dedicados à agropecuária, no estado, e foi responsável pela produção de 2,5 bilhões de litros de leite em 2007, volume que, monetarizado, significou um Valor Bruto da Produção (VBP) de R \$ 1,4 bilhão (Instituto Paranaense de Desenvolvimento Econômico e Social IPARDES, 2009a).

De acordo com Tarsitano et al. (2005), entre os agricultores familiares, a pecuária de leite é uma das principais atividades, presente em $36 \%$ dos estabelecimentos nacionais classificados como de economia familiar.

Cerca de $85 \%$ dos 5,3 milhões de estabelecimentos agropecuários do Brasil são considerados familiares. Representam, entretanto, apenas $31 \%$ da área e são responsáveis por $38 \%$ de toda a produção agropecuária, ocupando aproximadamente 15 milhões de pessoas (IBGE, 2006; DIEESE, 2011). Segundo o Núcleo de Estudos Agrários e Desenvolvimento Rural - NEAD/FIPE (2004), as cadeias produtivas da agricultura familiar no Brasil, em 2003, alcançaram o valor de R $\$ 156,6$ bilhões, ou 10,06\% do PIB nacional, com um crescimento de 9,37\% em comparação com o ano anterior. No mesmo período, as cadeias produtivas da agricultura patronal representaram $20,51 \%$ do PIB do país, com crescimento de 5,13\% sobre o ano de 2002. A agricultura de base familiar é de suma importância na produção de proteínas de origem animal, representando 59, 56 e $51 \%$ do PIB das cadeias de suínos, leite e aves, respectivamente. Estes números revelam que a agricultura familiar tem uma importância socioeconômica fundamental, tanto na geração de renda como na ocupação de mão de obra e no abastecimento de alimentos no país.

Este estudo pretende tipificar e mensurar o valor da produção leiteira da colônia de agricultores de base familiar denominada Quero-Quero, situada no município de Palmeira, PR, bem como relacionar sua importância na geração de renda aos produtores.

\section{MATERIAL E MÉTODOS}

O trabalho foi desenvolvido na colônia de agricultores familiares Quero-Quero, situada nas coordenadas geográficas $25^{\circ} 24^{\prime} 10^{\prime \prime} \mathrm{S}$ e $49^{\circ} 56^{\prime} 41^{\prime \prime} \mathrm{W}$, no município de Palmeira, PR, e que representa cerca de $0,5 \%$ da área total do município.

A metodologia de levantamento dos dados envolveu a aplicação de um questionário aos moradores da colônia. Foram aplicados 51 questionários, durante o mês de dezembro de 2009, perfazendo a totalidade de propriedades de colonos que apresentam alguma forma de produção agropecuária na colônia.

Os resultados foram compilados, tendo como premissa informações sobre a produção leiteira da colônia, bem como informações correlacionadas com os sistemas de produção. A estruturação do questionário foi estabelecida considerando-se três aspectos: a tipificação da propriedade; a caracterização do rebanho e do manejo adotado e o mercado e a renda.

Quanto à tipificação das propriedades, buscou-se a caracterização social com questões específicas referentes a pessoas ocupadas na propriedade, subdividindo-as entre pessoal de mão de obra contratada e de mão de obra familiar e, ainda, questões relacionadas com a caracterização fundiária, com questionamentos referentes à área total das propriedades e à área destinada à pecuária leiteira.

$\mathrm{Na}$ caracterização do rebanho e do manejo adotado, objetivou-se o esclarecimento das questões técnicas referentes à pecuária leiteira, com questionamentos específicos acerca de raças utilizadas, alimentação fornecida e mecanismos de higiene adotados.

Os questionamentos referentes ao mercado e à renda foram adotados com o objetivo do esclarecimento da dinâmica de comercialização mais adotada pelos produtores, bem como sua relação na geração de renda deles. 
De posse dos dados, buscou-se calcular, com base nos valores atuais de mercado (Dezembro de 2009), o valor bruto da produção da comunidade, bem como levantamento de informações referentes aos benefícios sociais da produção, tanto para a comunidade e seus moradores quanto para o município.

\section{RESULTADOS E DISCUSSÃO}

Observou-se que, segundo os critérios do Decreto $n^{\circ}$. 3.991 (Brasil, 2001), dos 51 produtores entrevistados, 46 $(90,2 \%)$ são caracterizados como agricultores familiares (Figura 1).

As propriedades estudadas e classificadas como sendo de agricultores familiares e que apresentam atividade leiteira somam 43 (93,4\% das propriedades familiares), sendo que, delas, $25(58,1 \%)$ apresentam apenas a atividade leiteira e dez $(23,2 \%)$ exploram também agricultura. Do total, seis $(13,9 \%)$ têm outra fonte de renda assalariada (incluindo trabalho diário, trabalho assalariado mensal, pensão, aposentadoria, etc.). Uma propriedade ainda explora avicultura e, outra, pecuária de corte. Esse resul- tado contraria uma tendência regional e estadual, demonstrada por IPARDES (2009a), o que pode ser explicado em função da amostragem realizada pela pesquisa, ou seja, somente as propriedades com atividade leiteira foram visitadas. Assim, entende-se que, na área em estudo, não é comum a diversidade de atividades das propriedades, ou seja, os produtores apresentam a característica específica de produção leiteira.

Entre os agricultores não familiares, a média de área foi de 158,10 ha, sendo que destes, em média, 41,46 ha são destinados à atividade pecuária. Quando observado o número de pessoas dependentes das referidas propriedades, encontra-se uma proporção de 56,46 ha para cada pessoa. Esses agricultores ainda contratam, em média, 2,6 trabalhadores fixos por propriedade e 1,2 por até 60 dias no ano, em cada propriedade.

Entre os agricultores familiares a área média de cada propriedade é de 26,31 ha, sendo destinados, em média, 20,14 ha para a atividade leiteira. A proporção de pessoas dependentes das propriedades aponta uma relação de uma pessoa para cada 6,33 ha, mostrando a grande importân-

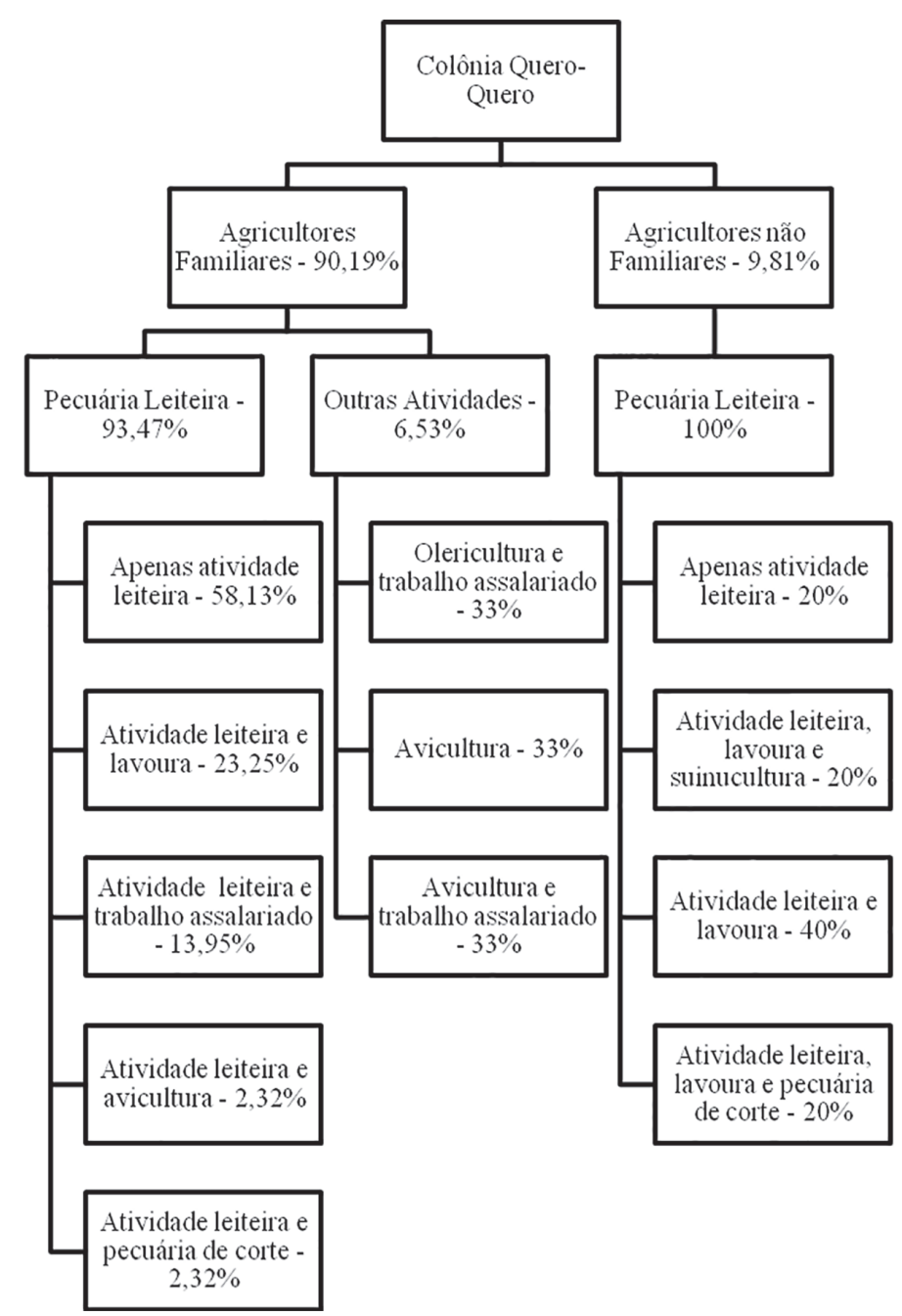

Figura 1: Diagrama demonstrativo da tipificação dos produtores entrevistados na colônia Quero-Quero, Palmeira, em 2009. 
cia social-fundiária da área em estudo. Esses produtores ainda contratam, em média, 0,71 trabalhador diário, durante 18,71 dias no ano. Quanto à mão de obra empregada nas propriedades familiares, constatou-se que em $75 \%$ dos casos há ajuda de filhos na atividade. De acordo com IPARDES (2009a), a área média das propriedades dos produtores de leite do Estado do Paraná é de 32,4 ha, mostrando que os agricultores familiares estudados possuem área média inferior à média estadual.

Com relação ao rebanho e a seu manejo, observa-se, na Figura 2, que a grande maioria (73\%) das propriedades possui rebanho de raça holandesa. Dados de estudos estaduais mostram uma média superior a 60\% (IPARDES, 2009a), sendo o restante distribuído entre as raças mestiças, Jersey e pardo-suíça. Segundo relatos dos moradores da localidade, a preferência por gado da raça holandesa apresenta um aspecto cultural, influenciado pela ascendência europeia dos agricultores familiares. Também se observa que a grande maioria utiliza monta natural para reprodução e apenas $23 \%$ dos produtores utilizam inseminação artificial, sendo que $8 \%$ dos produtores utilizam as duas técnicas. O índice de inseminação artificial é inferior ao da média estadual, que é de 32,6\% (IPARDES, 2009a).

Observou-se que $17 \%$ trabalham com a ordenha manual, índice pequeno em relação ao do manejo nacional leiteiro de agricultores familiares, pois, de acordo com Castro et al. (2011), no Brasil, 87,7\% dos agricultores familiares que exercem atividade leiteira realizam ordenha manual e que $100 \%$ das propriedades realizam duas orde- nhas diárias, sendo este um bom indicativo de manejo, visto que Zoccal (2004) comenta que o ideal são duas ordenhas diárias, desde o primeiro dia pós-parto, de preferência com 12 horas de intervalo entre elas.

Constatou-se que $42 \%$ dos produtores são integrantes de algum tipo de cooperativa da região, seja do ramo pecuário, seja do agrícola. Também se observou que 38\% dos produtores não recebem nenhum tipo de assistência técnica, sendo que $33 \%$ recebem assistência na lavoura e, $29 \%$, na pecuária. É importante ressaltar o fato de que as declarações dos entrevistados não diferenciavam, na maioria dos caso, a assistência técnica recebida, de algumas simples visitas, de forma não constante, por algum técnico (Médico Veterinário, na maioria dos casos).

Com relação à nutrição animal, observa-se que todas as propriedades que trabalham com pecuária leiteira fornecem ração concentrada aos animais (Figura 3).

Quanto ao fornecimento de silagem, 52\% das propriedades fazem silagem de milho, cuja plantação tem área média destinada de 8,6 ha. Em se tratando de silagem pré-secada de forragem, a grande maioria (65\%) não a utiliza, sendo que os que o fazem, disponibilizam área de 6,2 ha. Quase a totalidade das propriedades (98\%) utiliza pastagem anual de inverno, basicamente Aveia Preta (Avena sativa) e Azevém (Lolium multiflorium), destinando, em média, 17,0 ha para seu cultivo. Essa média é muito semelhante à estadual, ou seja, 16,6 ha (IPARDES, 2009a), enquanto $54 \%$ ainda fazem pastagem de verão (em média 6,4 ha).

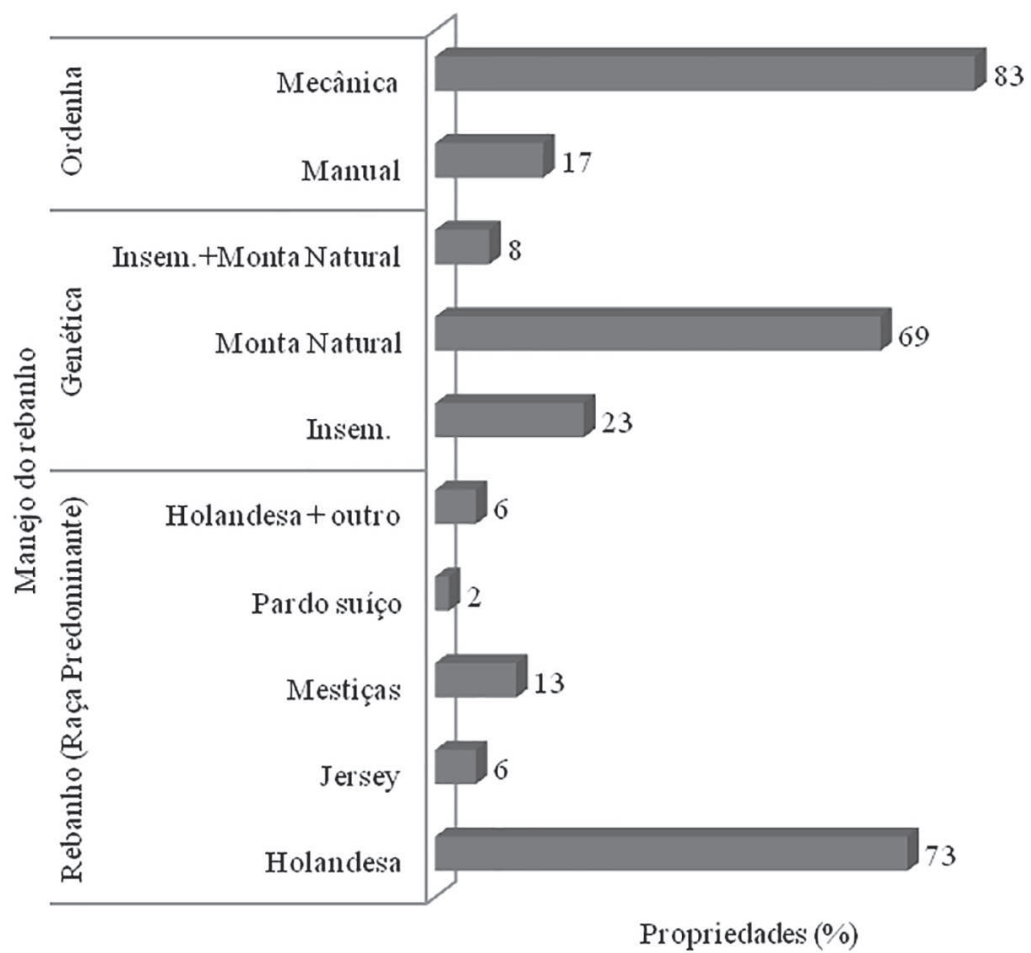

Figura 2: Caracterização do rebanho e do manejo adotado pelos produtores entrevistados na colônia Quero-Quero, Palmeira, PR, em 2009. 
Quanto à renda total da propriedade com pecuária leiteira, número considerável das propriedades familiares (58\%) apresenta a atividade como responsável por 75 a $100 \%$ da renda. Esses resultados mostram que, para a grande maioria das propriedades familiares, a atividade leiteira apresenta-se como de grande importância na geração de renda, enquanto, entre as grandes propriedades, isso ocorre em apenas 20\% delas (Figura 4). Esses resultados de renda corroboram o que é apresentado na Figura 3, ou seja, a relação direta entre a especificidade de renda das propriedades e o investimento na atividade com técnicas e manejos, como o fornecimento de ração e a utilização de silagem e de pastagem anual.

Analisando-se a produção (Tabela 1), observa-se que o rebanho total é de 1.948 cabeças. Destas, estavam em produção 967 vacas, ou seja, uma relação de 49\% de va- cas em lactação. Segundo Zoccal (2004), o número de vacas em lactação deve ser, no mínimo, $40 \%$ do número total de animais do rebanho. No caso da colônia estudada, essa relação está acima do mínimo ideal, sendo este um ponto positivo da produção da região. A produção atual obtida em dezembro de 2009 chega a 468.105 L mês ${ }^{-1}$ (313.005 litros oriundos das propriedades familiares e 155.100 dos demais produtores). Essa produção atinge extremos de 638.375 L mês ${ }^{-1}$ e 412.605 L mês ${ }^{-1}$, em julho e novembro, respectivamente.

A produtividade média observada foi de $16,14 \mathrm{~L} \mathrm{vaca}^{-1}$ $\mathrm{dia}^{-1}$, sendo que entre os agricultores familiares essa média é de 14,97 $\mathrm{L} \mathrm{vaca}^{-1} \mathrm{dia}^{-1}$ e 19,15 $\mathrm{L} \mathrm{vaca}^{-1} \mathrm{dia}^{-1}$ entre os demais produtores. Segundo IPARDES (2009a), a média estadual é de 10,9 $\mathrm{L} \mathrm{vaca}^{-1}$ dia $^{-1}$ e a da região centro-oriental (na qual se insere o município de Palmeira) é de 15,1 L

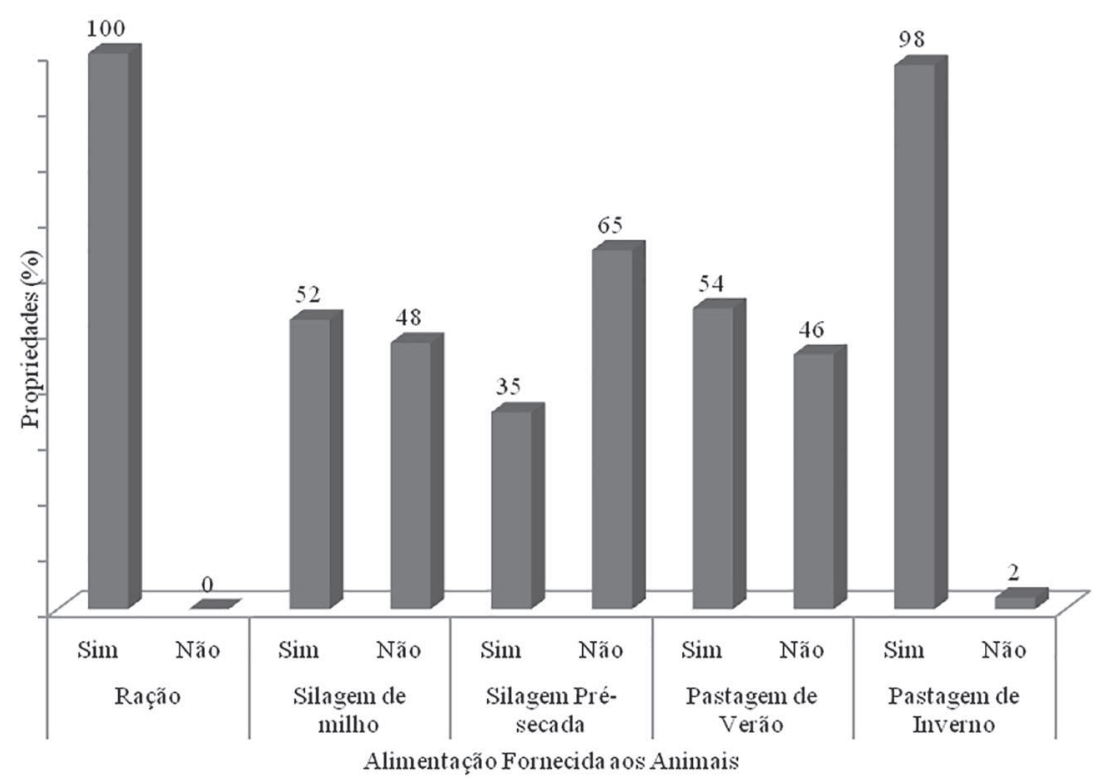

Figura 3: Tipo de alimentação fornecida aos animais pelos produtores entrevistados na colônia Quero-Quero, Palmeira, PR, em 2009.

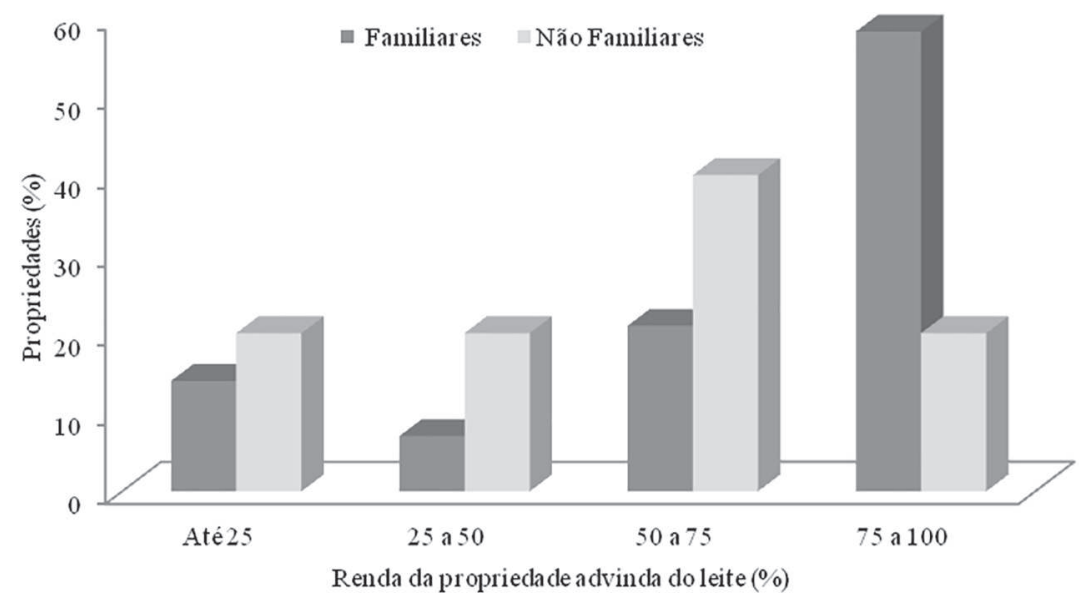

Figura 4: Percentagem da renda total advinda da pecuária leiteira nas duas tipologias de agricultores entrevistados na colônia QueroQuero, no município de Palmeira, PR, em 2009. 
Tabela 1: Dados referentes ao rebanho, produção e valores recebidos, bem como os valores brutos da produção (VBP) da colônia Quero-Quero, Palmeira, PR, em 2009

\begin{tabular}{|c|c|c|c|c|}
\hline & $\begin{array}{c}\text { Mês } \\
\text { de referência }\end{array}$ & $\begin{array}{c}\text { Agricultores } \\
\text { Familiares }\end{array}$ & $\begin{array}{c}\text { Demais } \\
\text { Produtores }\end{array}$ & Total \\
\hline Rebanho Total & Dezembro & 1.391 & 557 & 1.948 \\
\hline Animais em Lactação & Dezembro & 697 & 270 & 967 \\
\hline Produção Atual (L mês $\left.{ }^{-1}\right)$ & Dezembro & 313.005 & 155.100 & 468.105 \\
\hline Pico de produção $\left(\mathrm{L} \mathrm{mês}^{-1}\right)$ & Julho & 433.175 & 205.200 & 638.375 \\
\hline Menor produção $\left(\mathrm{L}^{\mathrm{mês}}{ }^{-1}\right)$ & Novembro & 264.405 & 148.200 & 412.605 \\
\hline Produtividade atual $\left(\mathrm{L} \mathrm{vaca}^{-1} \mathrm{dia}^{-1}\right)$ & Dezembro & 14,97 & 19,15 & 16,14 \\
\hline Valor médio atual recebido $\left(\mathrm{R} \$ \mathrm{~L}^{-1}\right)$ & Dezembro & 0,54 & 0,63 & 0,59 \\
\hline Maior valor médio recebido $\left(\mathrm{R} \$ \mathrm{~L}^{-1}\right)$ & Julho & 0,69 & 0,77 & 0,73 \\
\hline Menor valor médio recebido $\left(\mathrm{R} \$ \mathrm{~L}^{-1}\right)$ & Novembro & 0,52 & 0,63 & 0,58 \\
\hline \multirow{3}{*}{ Valor bruto da Produção (R\$ mês ${ }^{-1}$ ) } & Dezembro & $169.648,71$ & $98.333,40$ & $275.245,74$ \\
\hline & Novembro & $138.019,41$ & $93.958,80$ & $238.485,69$ \\
\hline & Julho & $298.457,58$ & $158.824,80$ & $466.971,31$ \\
\hline
\end{tabular}

vaca $^{-1} \mathrm{dia}^{-1}$, mostrando que, entre os agricultores familiares, a produtividade obtida supera a média estadual e se assemelha a média regional, porém, entre os demais produtores, a média de produtividade de $19,15 \mathrm{~L} \mathrm{vaca}^{-1} \mathrm{dia}^{-1}$ apresenta-se como sendo baixa. Dados regionais de cooperativas mostram médias de produtividade superiores a $24 \mathrm{~L} \mathrm{vaca}^{-1} \mathrm{dia}^{-1}$, entre grandes produtores leiteiros (Silva et al., 2008) e de produção leiteira em sistemas de confinamento total, no Estado do Minas Gerais, que é de 22,25 $\mathrm{L} \mathrm{vaca}^{-1} \mathrm{dia}^{-1}$ (Lopes et al., 2012).

Os valores médios recebidos pelos agricultores, por litro, variam de $\mathrm{R} \$ 0,58$ a $\mathrm{R} \$ 0,73$, entre os meses de novembro e julho, respectivamente. Observou-se ainda uma diferença entre os valores pagos para os agricultores familiares e os demais, da ordem de $11 \%$, em julho, e $18 \%$, em novembro, fato explicado pelo pagamento diferenciado por parte dos compradores, que leva em conta qualidade e quantidade do leite comercializado. No caso da qualidade, seguem-se adequações previstas na Instrução Normativa № 51 do Ministério da Agricultura - MAPA (Brasil, 2002), adequações já antecipadas ao prazo legal de sua aplicação em algumas propriedades, bem como por alguns compradores.

Calculando-se o Valor Bruto da Produção - VBP, visualiza-se que no mês de julho foi de $\mathrm{R} \$ 466.971,31$ mês $^{-1}$ e, em novembro, de R \$238.485,69 mês $^{-1}$. Este contraste de valores deve-se ao fato de que, em meses de menor produção (início do verão), coincidentemente se praticam os menores preços pagos aos produtores, contrariamente ao que ocorre nos meses de inverno.

Segundo IPARDES (2009b), com base nos dados de 2006, o município de Palmeira produz 128.989,04 $\mathrm{L} \mathrm{dia}^{-1}$. Observou-se que, na colônia em estudo, a média de produção total diária (considerando-se a variação de maior e menor produção ao longo do ano), é de 18.441,33 $\mathrm{L} \mathrm{dia}^{-1}$, ou seja, cerca de $14 \%$ de toda a produção leiteira do município, mostrando, assim, a grande importância da produção leiteira familiar da colônia para o município. Ainda segundo IPARDES (2009b), o VBP da produção leiteira para o município gira em torno de $\mathrm{R} \$ 2.354 .000,00$ por mês. Portanto, entende-se que, considerando-se o VBP médio mensal da colônia, cerca de $15 \%$ de todo o VBP da produção leiteira do município provém da área estudada.

\section{CONCLUSÕES}

A tipificação dos estabelecimentos, com base na estrutura agrária e nos sistemas de exploração e gestão das propriedades rurais da colônia Quero-Quero, indicou a predominância da agricultura familiar na comunidade.

A atividade leiteira apresenta algumas deficiências em relação a manejo do rebanho, porém, tem garantido boa perspectiva de renda para os agricultores, mostrando grande importância, não somente para a própria comunidade, com a geração direta de renda, mas também para o município, contribuindo significativamente para a sua economia.

\section{REFERÊNCIAS}

Brasil (2001) Decreto $N^{\circ}$ 3.991, de 30 de Outubro de 2001. Dispõe sobre o Programa Nacional de Fortalecimento da Agricultura Familiar - PRONAF, e dá outras providências. DOU, 31/ 10/2001, Seção 1, Página 3.

Brasil (2002) Instrução Normativa $\mathrm{N}^{\circ} 51$, de 18 de setembro de 2002. DOU, 20/09/2002, Seção 1, Página 13.

Castro KNC, Comunello E, Soares JPG, Gabriel AMA, Oliveira ER \& Negrão FJ (2011) Diagnóstico da pecuária leiteira no assentamento fazenda nova da lagoa grande em dourados, MS. Disponível em: <http://www.pubvet.com.br/uploads/ 91 fe617ba84785cb5949868435985ba8.pdf>. Acessado em: 15 de janeiro de 2014.

DIEESE (2011) Estatísticas do meio rural 2010-2011. 4 ed. São Paulo, DIEESE/NEAD/ MDA. 292p. 
IBGE (2006) Censo Agropecuário 2006: Brasil, Grandes Regiões e Unidades da Federação. Rio de Janeiro, IBGE. 777p.

IPARDES - Instituto Paranaense de Desenvolvimento Econômico e Social (2009a) Caracterização socioeconômica da atividade leiteira no Paraná: sumário executivo. Curitiba, IPARDES. $29 \mathrm{p}$.

IPARDES - Instituto Paranaense de Desenvolvimento Econômico e Social (2009b) Caderno Estatístico do Município de Palmeira. Curitiba, IPARDES. 23p.

Lopes MA, Santos G \& Carvalho FM (2012) Comparativo de indicadores econômicos da atividade leiteira de sistemas intensivos de produção de leite no Estado de Minas Gerais. Revista Ceres, 59:458-465

Martins PC (2004) Políticas públicas e mercados deprimem o resultado do sistema agroindustrial do leite. Juiz de Fora, Embrapa Gado de Leite. 160p.

Mezzadri FP (2005) Panorama da Pecuária Leiteira: Aspectos Internacionais - Nacionais - Estaduais. Disponível em: <http:/ / w w w. s e a b.pr.gov.br/arquivos/File/deral/ panorama_pecuaria_leiteira.pdf $>$. Acessado em: 15 de janeiro de 2010 .
NEAD/FIPE - Núcleo de Estudos Agrários e Desenvolvimento Rural / Fundação Instituto de Pesquisas Econômicas (2004) PIB das Cadeias Produtivas da Agricultura Familiar. São Paulo, NEAD/ Fipe/USP. 9p.

Silva HA, Moraes HSKA, Guimarães VDA, Hack E \& Carvalho PCF (2008) Análise da viabilidade econômica da produção de leite a pasto e com suplementos na região dos Campos Gerais. Ciência Rural, 38:445-450.

Tarsitano MAA, Fabrício JA, Sant'ana AL \& Proença ER (2005) Caracterização e perspectivas da pecuária leiteira e a agricultura familiar. In: $43^{\circ}$ Congresso da Sociedade Brasileira de Economia, Administração e Sociologia Rural, Ribeirão Preto, São Paulo. Anais, USP. p.1-15.

Zoccal R (2004) Cem recomendações para o bom desempenho da atividade leiteira. Juiz de Fora, Embrapa Gado de Leite. 7p. (Comunicado técnico, 39). 